\title{
Investigation of Legal Culture of Petition System
}

\author{
LI Huimin ${ }^{1, a}$ \\ ${ }^{1}$ School of political science and public administration, China university of political science and law, \\ Beijing 100088, China. \\ alihuimin@sina.com
}

Keywords: Petition system; Legal culture; Society with rule of law; Traditional culture

\begin{abstract}
Petition is an important social and cultural phenomenon in China's long-standing history. Petition is born with the existence of the country. But complete petition system with Chinese characteristics started in the founding of new China, it is considered to be a special human rights relief and political participation created by the communist party of China, playing important role in the communication and the relationship between national and citizen in different historical stages. From the particular perspective of the traditional legal culture, petition system in China and complaint behavior reflects the Chinese people living rules and logic, is a kind of life is the height of wisdom crystallization.
\end{abstract}

\section{Petition system}

\section{Concept and characteristics of petition system}

At present we don't have a unified concept of petition system, which still need to be studied. The theory about the views about the meaning of letters is more, now will have representative views summarized as the following:

The first point of view, namely the most general petition thinks that reporting refers to the social political exchanges activities reflect the will of individual or collective in the form of social writing and visiting.

The second view can be called a general definition. [1]According to this view, petition is generally considered letters visiting. It refers to social political activities to reflect the will of individual or collective social members by letter, telephone, telegram, access and other forms to social organization, managers. It usually includes two basic processes: the process that social members reflect the will by letters or visits to the social organization and the process of social organization managers to handle relevant issues.

The third point thinks, petition the people's letter visit. It represents that people ask for reception through writing to enterprises and institutions to make suggestions, comments, request and the activity of criticism in the party. Letters supervision is the people through the write or meet requirements banking supervision, to the relevant party and government organs and other state organs, administrative organs and their personnel duty behavior and into a behavior to present an opinion, proposal, request, criticism or complaint, complaints and accusations, reporting, and direct supervision of administrative organs and their staff a kind of system.

\section{Rights of the petitioner}

\section{1) Right to petition}

Petition is a way of citizens' freedom of expression, important democratic rights of citizens. Petition is the control of public power, an effective way of citizen oversight of public power. Historical experience and lessons show that lack of supervision of power will inevitably lead to corruption. In modern society, rapid expansion of public power is a global problem. [2] How to effectively balance and supervision of state power is an important subject of constitutionalism. In such a strong administrative tradition, dominate social process of state power, and rush to the transformation of the country to the rule of law, due to the transformation of the society, the lack of rules caused by a variety of administrative law, social injustice phenomenon appears frequently. So it is especially important to restrict administrative illegal behavior, safeguard citizens' legal rights through letters. 


\section{2) Rights and obligations of petitioner}

The right of the petitioner is a legal means in reporting activities to gain or maintain its own interests. The right of the complainant includes seven aspects, as well as the characteristics of three aspects: first, it is a kind of law from the form of the complainant rights. As legal rights, it must be a form of legal norms, which have specific embodiment in the constitution, the complaint reporting regulations and complaint reporting regulations. Second, the complainant rights motioned a possibility; implying complainant can acquire from the legal norm an act or omission, or require the ability to act or omission of others. When the complainant enjoy and exercise the power and possibility into reality, the complaint reporting talent can be called truly enjoy a legal rights. Third, the petition's rights marked the complainant free range of legal limit, not transfer its legal qualification and endowed with a complainant's subjective intention.

\section{Root of petition}

Although there are many problems in petition, but the relative to litigation, there are still many people keen on reporting. Outside the government building, it is usually found that some people crowds around the door of the government authorities and law enforcement, hands with the white cloth written with "wronged", ready to "attack".

\section{Systematic roots}

Due to the situation of contemporary Chinese administrative judicial intervention is still very common, administrative letters and visits has become the main body in their letters. This maintains the individual justice in certain circumstances, but it is as the cost of the detriment of the rule of law. But people's thinking is simple and direct, he looking for the one with big power and can pay them justice.

First is from power. In the field of administration, one of the most common phenomenons is the leadership instructions. No matter how many quantities of the law, it can't keep up with the organs at higher levels of instruction, important leadership instructions. [3]The effectiveness of the instructions is greater than law is an indisputable fact, which also creates conditions for the judicial administrative intervention.

Second is from the judicial status. On one hand, judicial is attached to administrative, subject to the administration, on the other hand, the exercise of judicial power also often adopt the administrative mode. From administrative uniform of judge before to today's robe, in fact the court cannot be separated from the category of the administrative management although its form has judicial neutrality.

Three is from the difficulty of execution. The difficulty of execution is common in administrative cases while reporting case may be relatively smooth. By rights, legal remedy should be the most authoritative and most powerful relief way for judicial decisions, carry out should also be more effective than a complaint reporting. But in China's political system, judicial administrative can hardly intervene, the "administrative litigation law" also regulates that the court can only do a handful of administrative behavior change.

Structural defects of the system lead to national encountered problem that is to find the most useful person or department you think, thus forming the thought that ask government for help when encounter difficulty, and the government also takes it as it is his duty. With the success of some petition case, more and more people believe that petition is useful than judicial, judicial status by the greater impact.

\section{Cultural roots}

In the conflict of almost of the west society, the authority's decision is fair because the decision is made by the judicial organs. Under the influence of such litigation culture, because the judicial organ has the absolute authority, even the parties and the public think the judge's ruling injustice, they can take to it consciously. The federal court judges Jackson said that "The reason why my decision is ultimate and not to overthrow am not I making judgment of the right, on the contrary, because I am judgment, my decision is not to overthrow". But in our country, thousands of years of rule of man make it fundamentally lack of faith in law. People are always trying to petition the way 
to change the judicial referee; also some people do this in reality. From the point of the mentality of a complainant, almost the complainant's entire subconscious has a lingering official complex, in the feudal society drum voice grievances; stop the car very fact scenario, which has no essential difference between the handling of complaint reporting.

\section{Economic roots}

Seek relief through judicial means often means to pay high costs, such as filing fee, transportation, judicial word, and so on. While petition doesn't charge any fee, sometimes complaint reporting agencies entertain accommodation and buy return ticket. Through litigation to solve the problem that is a big burden for the disadvantaged.

Though it takes more than a little cost from writing letters to its stop, the cost is paid for several times, not high for each time, usually in the range.[4] Petition has become a right relief way the weak cannot ignore.

\section{Social roots}

Now there is a phenomenon in the society, the success of letters and visits in the complaint is not much, but very easy in the potential of reporting group, among which, the news media reports also willing to undertake the relevant national office working personnel is also very willing to propaganda, can be used as his achievements. However, the vast majority of cases didn't get very good handling complaint reporting social so hard to get more attention. And successful letters can be quickly solved and some can even get unexpected extra income.

Because the whole society has paid great attention to the problem of letters and visits, it is easy to prompt people to make errors in judgment of complaint reporting, expecting too much of a complaint reporting, thinking petition can easily solve all the problems, which inspire potential complaint reporting group to select petitions to solve the problem.

\section{System rules and punishment in public life}

\section{Game theory analysis in cooperation}

Classical theory that studies the individual behavior choice in the interactive environment and its results is game theory. Among them, the prisoner's dilemma is one of the most commonly used models. This model is widely used in economics, computer science, biology, sociology, law, history and political science studies, therefore many versions with change according to the needs are born. Of course, the basic principle of each version is the same.

\begin{tabular}{|c|c|c|c|}
\hline & & \multicolumn{2}{|c|}{ A } \\
\hline & & Cooperate & Betray \\
\hline \multirow[b]{2}{*}{ B } & Cooperate & $\begin{array}{l}\mathrm{R}= \\
\mathrm{R}=3\end{array}$ & $S=0$ \\
\hline & Betray & $\begin{array}{l}\mathrm{S}=\mathrm{c} \\
\mathrm{T}=5\end{array}$ & $\mathrm{P}=1$ \\
\hline
\end{tabular}

Figure 1. Game model of the prisoner's dilemma

Because the broad applicability of the prisoner's dilemma and the mutual betrayal is Nash equilibrium, it really made many researchers in the real world to be of extreme pessimism. They found little aspect like interpersonal relationships to international politics; they can all be explained by the prisoner's dilemma. Many researchers note, however, the empirical evidence abounds in cooperation, small to (marriage), to the international agreement. Seems to be real situation isn't so bad. If so, how explain this cooperation in the prisoner's dilemma "paradigm" became a valuable 
theoretical problem.

\section{Punishment for violations in petition}

Punishment must have quite strength so as be of fearing power. Punishments' expected effectiveness depends on two factors: the severity and frequency. Method of modern economics argues that effective punishment must make defectors expected losses over he gains for his betrayal. Punishments' expected loss is the product of the probability of the actual loss of punishment and punishment; the former said the harshness of punishment, while the latter said the credibility of the punishment.

From the point of view of the discount rate, some commonplace will present a different picture. For example people usually think that the monkeys in the ancient Chinese fables "chop and change" are too simple, sometimes naive. But modern economics discount rate suggests that may not be entirely true. If the discount rate is the same, then the larger the future interests of the absolute number is, the greater the amount of discount will be. For example, if someone promised to give you 1.1 million RMB now, but there are two kinds of forms of distribution. The first is now to give you one hundred thousand now, one million three years later; the second is now to give you one million now, one hundred thousand three years later. Suppose the discount rate to be $W(0 \leq W \leq 1)$, if $W \neq 0$, people will choose the latter, whose reason is very simple, because $10+100(1-W)^{3}<100+10(1-W)^{3}$. In fact, isn't the monkey in the fable of the chop and change makes such a choice? The expected revenue of monkey is $U_{1}$, then $U_{1}=3+4(1-Q)+3(1-Q)^{2}+\ldots+3(1-Q)^{N-2}+4(1-Q)^{N-1}$. Under chop and change rule, suppose the expected revenue to be $U_{2}$, then $U_{2}=4+3(1-Q)+4(1-Q)^{2}+\ldots+4(1-Q)^{N-2}+3(1-Q)^{N-1}$. Because $U_{2}=4+3(1-Q)+4(1-Q)^{2}+\ldots+4(1-Q)^{N-2}+3(1-Q)^{N-1}=\frac{1-(Q-1)^{N}}{2-Q}$, and $0 \leq Q \leq 1$, so $\frac{1-(Q-1)^{N}}{2-Q} \geq 0$, only when $Q=0, \frac{1-(Q-1)^{N}}{2-Q}=0$, and $U_{1}=U_{2}$. On other condition, $U_{1}<U_{2}$.

We can conclude that the monkeys makes wise choice.

\section{Paths for the legislation of petition system in our country}

\section{Reconstruction of petition system in China}

\section{1) Improve the petition's legislative norms}

The petition law should be formulated as soon as possible to make the petition system in China has law to follow and the reasons are as follows. First, from legal principle, petition has the property of constitutional rights, so it is not suited to regulate the constitutional position of petition with administrative or local rules and regulations. The masses call for national reporting method is becoming more and more strong. Second, the new regulations still exist many defects and insufficiency. For example, the new regulations doesn't cover all national petition, just cover the administrative organs and their personnel, not including legislation, the judicial organs and their staff; On the legislative process, it had not held a special legislative hearing, not released draft regulations of the full text and comment through the media, the revision work was basically in a closed state, legislative lack of openness and transparency.

\section{2) Stripping the relief function of petition system}

At present, according to the statistics from provincial, city and county, it shows that petition that belongs to defy the administrative punishment decisions, court of complaint letters and calls for the government to solve practical problems, accounts for about $30 \%-40 \%$ of the total ; petition belong to impeach and accuse accounts for about $20 \%$ of the total. Suggestions and opinions put forward for the government's decision accounts for about $10 \%$ of the total. There is no denying the fact that, a lot of original case can be solved by way of administrative reconsideration and the judicial action of problems got into the channels of complaint reporting. As the right to judge and suggest is 
restricted by citizens' political enthusiasm, level of education and ability to participate in conditions, while the exercise of the right of appeal, complaint, the right of accusation has no requirement, the imbalances comes into being between rights to judge, suggest, and rights to accuse and charge . In a way this situation alienated the democratic nature and function of petition.

\section{Perfection of other supporting legal system}

Letters and give full play to effective legal system in our country, also need to perfect a series of supporting the legal system, do the following two links, only in this way can enlarge the orderly political participation of citizens, establish judicial authority finally, China's petition system to obtain a new life.

1) Improve the citizens' right to know and the open system of national government affairs

In 1950, the American society of news editors established the freedom of information board to seek counseling free circulation. Because at that time, the government refused to provide ongoing interview material from time to time, this institute asked authoritative scholar in the society to conduct a formal research about freedom of information. The collection of the research results was published in 1953, which was the citizens' right to know, public records and its method of the right of access of the review process. In 1954, the federal government refused to recognize nuclear test has led to a deadly radiation in the south Pacific Ocean . Will to dig the truth of the reporters have been hit a wall in front of the government, and adapt to this trend, the rise of the movement of led to a "right to know". Based on the fact that national has a right to know about the government's activity, the reporter to satisfy citizens' right to know, therefore, should be taken to the freedom and report. Because of the news media emphasize the protection of citizens' right to know ", caused a constitutional express a major change in the legal theory of freedom and its significance, influence the U.S. Supreme Court's understanding of freedom of expression. Through the understanding of the history of the United States, people's "right to know" is derived out from the principle of national sovereignty and open government.

\section{2) Combination of administration and supervision system}

The powers of the heterodoxy need self-discipline. From the balance of power and right, in addition to monitoring by the society, the government should also be bound by internal self mechanism, achieving self-discipline, such as the administrative supervision system of our country. To further strengthen the position and function of reporting in administrative supervision, perfect the administrative supervision system with a complaint reporting as the core.

In the past 50 years of experience, democracy established by the government after 1949 though emphasize that people can the supervise the government, but its openness is still insufficient. Legislation takes the internal supervision as the orientation, supervision through direct confrontation of the legal is very weak. The current administrative supervision system in China must be started up by the administrative organ, the administrative relative person administrative supervision program cannot be started. Petition is common civil complaint form in our country in real life. But administrative supervision in the sense of petition is the important foundation of supervisory organs start monitoring program and information sources. It mainly refers to the administrative supervision organization accept and handle the mail, visit reports from citizens to express complaints.

\section{Summary}

In China, petition is a deeply complex and heavy topic for officials and scholars. Petition system has reached a key intersection, reform for which is urgent. However, the reform of the petition system is complicated system engineering, will not complete by a law or modifies a set of regulations. Therefore, how to perfect this system to make the system get rid of the trace of the rule of man as soon as possible, takes to the track of the rule of law, it not only need to practice more, also need to make more efforts to this theory. But it is believed that as long as we are able to emancipate the mind, seek truth from facts, draw lessons from foreign experience, and speed up the pace of reform, petition will be on the track of the rule of law definitely. 


\section{References}

[1] Wang Xuelian. Look petition system innovation from the maintenance of social stability [J]. Journal of the Chinese people's public security university. 2004, (4). 39.

[2] Chenyan. The plight and solution way of petition system [J]. Journal of Gansu province adult education college of political science and law, 2005 (1): 94-96.

[3] Sun Liping. Build system arrangement on the basis of right [N]. Southern weekend, 2004(1), 1.

[4] Xuting, On private aid and force. Beijing: China University of political science and law press, 2005. 